\title{
Fear of falling and associated factors among older people living in Bahir Dar City, Amhara, Ethiopia- a cross-sectional study
}

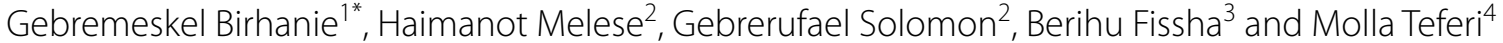

\begin{abstract}
Background: Fear of falling (FOF) is the most common public health problem, which can lead to loss of confidence, reducing physical and social activities, depression, loss of mobility, increased risk of falls, physical weakness, and strong negative impact on an older people's quality of life. However, studies in developing country were lacking, particularly in the study area. Therefore, the aim of the current study was to fill this gap in the study area in particular and the country in general. The purpose of the current study was to assess the prevalence and associated factors with fear of falling among older people 60 years and older who were living in Bahir Dar city, Ethiopia.

Methods: A community based cross sectional study design was conducted with a total sample size of 527 participants and multistage random sampling technique was used to select the study participants. The fall efficacy scale tool was used to develop the questionnaire. Data were coded, cleaned and entered into SPSS version 23 for analysis. Multi-collinearity and model fitting were checked. In bivariate logistic regression analyses, variables with $p$-value $<0.25$ were considered as potential candidates for multivariable logistic regression analyses. A variable with $p$-value $<0.05$ at $95 \% \mathrm{Cl}$ was considered as statistically significant. Finally, the odds ratio and 95\% confidence interval were estimated and interpreted.

Results: A total of 481 participants was included in this study. The prevalence of fear of falling among the older people was 59.9\% (95\% Cl; 55.7-64.4). Fear of falling was significantly associated with the following variables:- advanced age $(\mathrm{AOR}=4.01,95 \% \mathrm{Cl} ; 1.65-9.74)$, female $(\mathrm{AOR}=4.25,95 \% \mathrm{Cl} ; 2.25-8.01)$, lower education level $(\mathrm{AOR}=2.77,95 \% \mathrm{Cl}$; $1.12-6.82)$, anxiety $[A O R=9.03,95 \% \mathrm{Cl} ; 4.78-17.07)$, confirmed medical conditions ( $\mathrm{AOR}=2.01,95 \% \mathrm{Cl} ; 1.03-3.91)$ and walking aids used $(\mathrm{AOR}=13.82 ; 95 \% \mathrm{Cl} ; 5.21-36.63)$.
\end{abstract}

Conclusions: A moderate prevalence of fear of falling was observed. The major associated factors were advanced age, being female, lower educational level, anxiety, confirmed medical conditions and walking aids used. Hence, we recommend the need of rehabilitation programs that enable healthy aging and further rigor research is recommended.

Keywords: Associated factors, Fear of falling, Prevalence, And older people

*Correspondence: gebriphysio@gmail.com

1 Department of Physiotherapy, School of Medicine, College of Health Sciences, and Tibebe Giyon Specialized Hospital, Bahir Dar University, Bahir Dar, Ethiopia

Full list of author information is available at the end of the article

\section{Background}

Fear of falling (FOF) is an ongoing concern about falling that ultimately limits the undertaking of daily activities and also known as a post-fall syndrome, or post-fall phobia which is defined as a fearful expectation of a fall [1,2]. Fear of falling is one of a consequence to fall [3]. 
It is a major health problem among older people living in the communities who have and have not a history of falling [4-7]. Recent studies showed that $26-55 \%$ of older people can experience the FOF [8, 9]. The reported prevalence of FOF varied between 3 and $85 \%$ [5]. In the U.S.A, FOF is a common problem among older people, with an incidence ranging from 21 to $85 \%$ [10] and approximately one-third of them had activity limitations [11]. In Africa study conducted among older people living in the community of Egypt, prevalence rate of FOF was $64.4 \%$ [12].

Fear of falling is known to be associated with old age, female gender, poor vision, frailty, previous history of falls, lower levels of economic resources, poor health, decreased physical function or mobility, the presence of environmental hazards, decreased social contacts, and living alone, depression, anxiety, and a reduced ability perform tasks associated with everyday living $[3,5,12-17]$.

Older people with FOF often change their gait, decrease their activity, or attempt to use assistive devices to prevent falling [13]. It may leads to loss of confidence, reducing both physical and social activities/interaction, depression, loss of mobility and independence, risk of future falls and associated mortality, increased physical weakness, and the risk of nursing home admission. These consequences can have a negative impact on older people's quality of life and economic burden on their families/ or caregivers [16].

Although extensive research was conducted on the burden and determinants in developed countries, there was limited research on FOF among older people living in developing countries, including sub- Saharan Africa countries like Ethiopia. Thus, the present study aimed to assess the prevalence and associated factors of FOF among older people living in the city of Bahir Dar, Ethiopia.

\section{Methods}

\section{Study area and study period}

Bahir Dar is the capital city of Amhara national, regional, state, located in the northwestern part of Ethiopia, at a distance of $565 \mathrm{~km}$ far from Addis Ababa. According to the Ethiopian central statistics agency, the total population of the city is $\sim 180,174$ people in 2007 [18]. Its astronomical location is $11^{\circ} 35^{\prime}$ north latitude, $37^{\circ} 23^{\prime}$ east longitude and $1799 \mathrm{~m} / 5902 \mathrm{ft}$. above sea level [19]. The administration of the city has six (6) sub city and a total of 26 kebeles. The study was conducted on older people living in the city of Bahir Dar, Ethiopia, from April 1 to May 15, 2019.

\section{Study design and population}

A community-based cross-sectional study design was conducted. All older people aged 60 and older who live in the city of Bahir Dar have been the source of the population. All older people 60 years and older living in selected kebeles during the study period were included. Older people who were not able to communicate and unable to walk independently, with or without a walking support were excluded.

\section{Sample size determination}

For the first objective, based on the data obtained from Bahir Dar city administration bureau of labor and social affairs from a survey conducted in 2018, the total number of older people who were living in the city was 3341 and the profile of all older people living in the city was given by name, age, sex and full address [19]. The sample size was determined by estimating $5 \%$ margin of error, $95 \%$ confidence interval (alpha $=0.05$ ) and the prevalence of FOF was (64.4\%) attributable to a recent similar study in Africa, Egypt 2018 [12]. Based on this assumption, the sample size was determined by using single population proportion formula;

$$
\mathrm{n}=\frac{\mathrm{z}^{2} \mathrm{p}(1-\mathrm{p})}{\mathrm{d}^{2}}
$$

Where; $\mathrm{n}=$ initial sample size, $\mathrm{p}=$ proportion of success, that is the prevalence of FOF in older people, $(1-p)=$ not a proportion of success, that is not FOF in older people, $\mathrm{Z}$ a/2 = critical value for normal distribution at $95 \% \mathrm{CI}(1.96)(Z$-value at alpha $=0.05), \mathrm{d}=$ margin of error that is acceptable, $5 \%(0.05)$.

$$
\begin{gathered}
\mathrm{n}=\frac{(1.96)^{2}(0.644 \times 0.356)}{(0.05)^{2}} \\
\mathrm{n}=352.29 \approx 353
\end{gathered}
$$

By using population correction formula to get optimum sample size $\mathrm{N}=[\mathrm{n} / \quad(1+\mathrm{n} / \mathrm{N})]=[353 /$ $(1+353 / 3341)]=319$, since the population is less than 10,000. After Appling 1.5 multiplying factor for the design effect the sample size was 479 . By adding $10 \%$ non-response rate and minor adjustment the total sample size was 527 older people.

The sample size for objective two was calculated based on the assumption; FOF developed for those who had an exposed with depression is being $53.6 \%$ and those who had no depression is being 30.6\% FOF [6]. Assuming 5\% margin of error (d), 95\% confidence level (alpha, $\alpha=0.05$, two tailed) and $80 \%$ power to detect the assumed difference. This was calculated using the Epi Info 7 statistical software to get the optimum sample size with ratio $=0.22$, the final calculated sample size was 271 on 
Fleiss w/CC. After adding 10\% non-response rate and minor adjustment the total sample size was 298 older people. Therefore, the total sample size of this study was 527 older people.

\section{Sampling technique and procedure}

A preliminary survey was conducted in 2018 by the Bahir Dar city labor and social affairs administration office to find out about the total number of older people residing in Bahir Dar city and the total amount of older people was found to be 3341 . The administration of the city has six (6) sub city (kefleketema) and a total of 26 Kebeles. A multistage random sampling technique was employed to select the study participants. In the first stage, 13 out of 26 kebeles (50\% of the total area) were selected by simple random sampling technique (Fig. 1). A total number of households were obtained from the respective administrative areas and used to calculate the sampling fraction. Sampling interval, $K^{\text {th }}$ was calculated by $N / n$, $1833 / 527=3.47 \approx 4$. The starting household was identified by the lottery method and every 4th household elderly individual from each kebele was recruited for the study until the appropriate sample size was reached. Occasionally, when two or more individuals were eligible in a household, only one was selected by lottery method.

\section{Data collection tool, methods and procedures}

The data were collected by interviewing the participants using a semi-structured questionnaire that was adapted from related literatures (Additional file 1) and standard

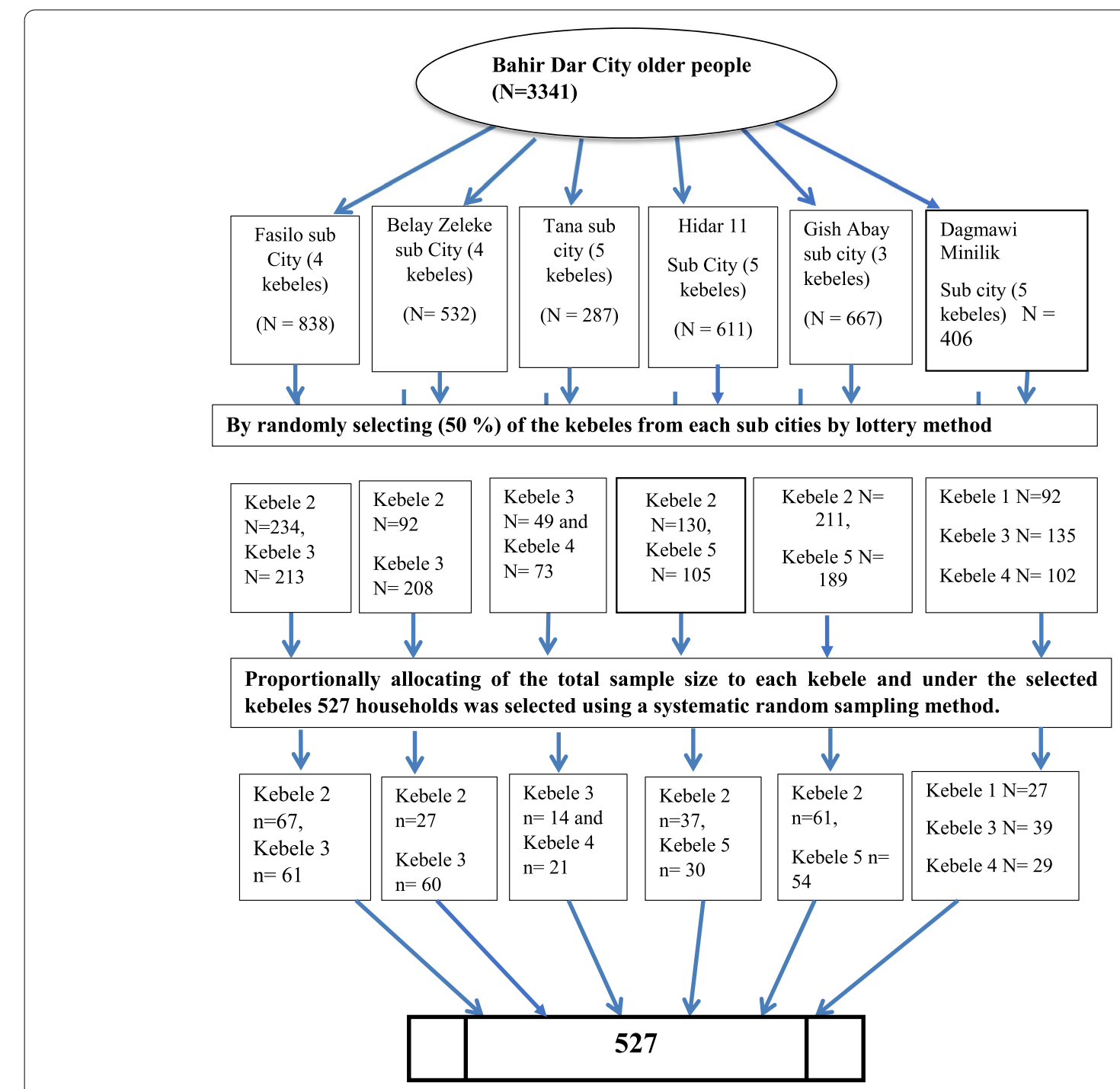

Fig. 1 Schematic presentation of sampling procedure among older people in Bahir Dar City, Ethiopia 
questionnaire was adopted from tools (i.e. FES-I scale, GDS-SF scale, GAD-7 scale and Katz index of independent in ADL tool) [19-24]. Falls Efficacy Scale-International (FES-I):- contains 16 items, with scoring based on a 4-point. Total score ranges from 16 to 64 points; 16 meant no fear, 17-32 little fear, 33-48 moderate fear, and 49-64 intense fear $[25,26]$. The Geriatric Depression Scale-Short Form (GDS-SF) was used to screen for depressive symptoms in this study. The 15 items in the GDS-SF were extracted from the original 30-item GDS. Interpretation of the score (a score of 0 to 5 is normal, a score $>5$ suggests depression and a score $\geq 10$ is almost always indicative of depression) [22]. The original General Anxiety Disorder (GAD-7) was applicable in measuring the respondents' level of anxiety and consists of seven multiple choice questions. Total score ranges from 0 to 4 is minimal anxiety, 5-9 mild anxiety, 10-14 moderate anxiety and a score greater than 15 has severe anxiety [23]. The adopted questionnaire was included, sociodemographic variables (Age, sex, marital status, household income, educational level and body mass index), psychosocial factors (anxiety, depression, social support and physical exercise), fall-related factors (history of falling, and Injury with fall), disease and treatment related factors (disease conditions, Activity of daily life (ADL), number of co-morbidity and number of type of medications used) and environmental level factors (discomfort in neighborhood environment and walking aids) (Additional file). Data collectors were trained and the informed consent was obtained from each participant. The weight scale tool specification TIANSHA $=2003 \mathrm{~A}$, capacity: $11 \mathrm{lb}$. 5 kg - $400 \mathrm{lb}$. / $180 \mathrm{~kg} / 28$ St 8 lbs., Battery: CR2032 Lithium Battery was used to measure weight and height were measured using tape measures tool specification WIN TAPE, (FT-070). Height and weight were measured after the end of the interview. Data collectors and supervisors were trained.

\section{Operational definitions \\ Fear of falling}

Is positive when a cut-point for FOF as scores of FES-I was $>23$. This means a total score of FES-I scale is from 24 to 64 on the numerical rating scale $[18,20,21]$.

\section{Older people}

The age at which a person becomes 60 years and above refer to the older people $[4,6,12,27-32]$.

\section{Physical exercise}

Is any kind of moderate - intensity exercise (such as walking, cycling, sports or planned exercise and strength exercise) done at least $150 \mathrm{~min}$ per week [33, 34].

\section{Data quality control issues}

To ensure the quality of data all the necessary measures were done before, during and after the actual data collection. A valid and reliable instrument was used for the data collection. All data collectors and supervisors were given one-day training about the purpose of the study, details of the data collection instrument (questionnaire), interviewing techniques, the importance of privacy and insuring confidentiality of the respondents.

The original English version of the questionnaire was translated into Amharic and re-translated back into English to maintain its consistency. Pretest was conducted on $5 \%$ of the total sample size. The questionnaire was reviewed and checked for completeness, accuracy and consistency by supervisors and investigators.

\section{Data processing and analysis}

The collected data were coded and cleaned and then it was entered into SPSS version 23 packages for analysis. Descriptive statistics, frequency and percentages, mean and standard deviations were used to describe the findings. Multi-collinearity was checked by variance inflation factor (VIF) cutoff point $<10$. Model fitness was checked by Hosmer- Lemeshow test. Bivariate logistic regression analysis was used to determine which variables had an association with FOF. In bivariate logistic regression analyses, variables with $p$-value $<0.25$ were considered as potential candidates for multivariable logistic regression analyses. All possible predictors which were significant in the bivariate analysis were included in the multiple logistic models. A variable with $p$-value $<0.05$ at $95 \% \mathrm{CI}$ was considered as statistically significant. Finally, AOR with $95 \% \mathrm{CI}$ at $p$ - value of $<0.05$ was reported.

\section{Results}

Socio-demographic and personal characteristics among older people 60 years and older

Among the total 527 study participants, 481 of them completed the interview with a $91.2 \%$ response rate. The majority of the participants were female $(n=251$, $52.2 \%)$ with a mean age of 67.9 years $(\mathrm{SD}=7.6)$. Almost half $(n=271,56.3 \%)$ of were married with the median monthly household income of 890 Ethiopian Birr. Four hundred nineteen participants (87.1\%) declared that they completed lower level of education and most participants had normal BMI score $(n=398,82.7 \%)$ (Table 1).

\section{Psychosocial level characteristics}

Of the total study participants, $(n=224,46.6 \%)$ had anxiety and about $(n=419,87.1 \%)$ had depression. 
Table 1 The descriptive characteristics of FOF among study participants in Bahir Dar city, Ethiopia $(n=481)$

\begin{tabular}{|c|c|c|c|c|}
\hline \multirow[t]{2}{*}{ Variables } & \multirow[t]{2}{*}{ Categories } & \multirow[t]{2}{*}{ Frequency, $n(\%)$} & \multicolumn{2}{|l|}{ FOF } \\
\hline & & & Yes, n (\%) & No, $\mathrm{n}(\%)$ \\
\hline \multirow[t]{2}{*}{ Sex } & Female & $251(52.2)$ & $177(70.5)$ & $74(29.5)$ \\
\hline & Male & $230(47.8)$ & $111(48.3)$ & $119(51.7)$ \\
\hline \multirow[t]{2}{*}{ Age } & $60-70$ & $351(73.0)$ & $170(48.4)$ & $181(51.6)$ \\
\hline & $\geq 71$ & $130(27.0)$ & $118(90.8)$ & $12(9.2)$ \\
\hline \multirow[t]{2}{*}{ Marital status } & Currently Married & $271(56.3)$ & $141(52.0)$ & $130(48.0)$ \\
\hline & Currently Unmarried & $210(43.7)$ & $147(70.0)$ & $63(30.0)$ \\
\hline \multirow[t]{3}{*}{ Body mass index (BMI) } & $<18.5$ & $11(2.3)$ & $8(72.7)$ & $3(27.3)$ \\
\hline & $18.5-24.9$ & $398(82.7)$ & $229(57.5)$ & $169(42.5)$ \\
\hline & $\geq 25$ & $72(15.0)$ & $51(70.8)$ & $21(29.2)$ \\
\hline \multirow[t]{2}{*}{ Monthly Income } & $\leq$ ETB1752 (US\$ 60.98) & $304(63.2)$ & $195(64.1)$ & 109 (35.9) \\
\hline & $\leq$ ETB1752 (US\$ 60.98) & $177(36.8)$ & $93(52.5)$ & $84(47.5)$ \\
\hline \multirow[t]{2}{*}{ Education status } & Lower level education & $419(87.1)$ & $270(64.4)$ & 149 (35.6) \\
\hline & Higher level education & $62(12.9)$ & $18(29.0)$ & $44(71.0)$ \\
\hline \multirow[t]{2}{*}{ Anxiety } & Yes & $224(46.6)$ & $190(84.8)$ & $34(15.2)$ \\
\hline & No & $257(53.4)$ & $98(38.1)$ & $159(61.9)$ \\
\hline \multirow[t]{2}{*}{ Depression } & Yes & $419(87.1)$ & $272(64.9$ & $147(35.1)$ \\
\hline & No & $62(12.9)$ & $16(25.8)$ & $46(74.2)$ \\
\hline \multirow[t]{2}{*}{ Social support } & Yes & $330(68.6)$ & $201(60.9)$ & $129(39.1)$ \\
\hline & No & $151(31.4)$ & $87(57.6)$ & $64(42.4)$ \\
\hline \multirow[t]{2}{*}{ Physical exercise } & Yes & $80(16.6)$ & $24(30.0)$ & $56(70.0)$ \\
\hline & No & $401(83.4)$ & $264(65.8)$ & $137(34.2)$ \\
\hline \multirow[t]{2}{*}{ History of falling } & Yes & $103(21.4)$ & $90(87.4)$ & $13(12.6)$ \\
\hline & No & $378(78.6)$ & $198(52.4)$ & $180(47.6)$ \\
\hline \multirow[t]{2}{*}{ Injury with fall } & No & $52(10.8)$ & $43(82.7)$ & $9(17.3)$ \\
\hline & Yes & $51(10.6)$ & $47(92.2)$ & $4(7.8)$ \\
\hline \multirow[t]{2}{*}{ Activity of daily life } & Functional limitation & $4(0.8)$ & $4(100.0)$ & $0(0.0)$ \\
\hline & No functional limitation & $477(99.2)$ & $284(59.5)$ & $193(40.5)$ \\
\hline \multirow[t]{2}{*}{ Number of types of medications } & $0-3$ & $439(91.3)$ & $250(56.9)$ & $189(43.1)$ \\
\hline & $\geq 4$ & $42(8.7)$ & $38(90.5)$ & $4(9.5)$ \\
\hline \multirow[t]{2}{*}{ Confirmed medical problems } & Yes & $276(57.4)$ & $209(75.7)$ & $67(24.3)$ \\
\hline & No & $205(42.6)$ & $79(38.5)$ & $126(61.5)$ \\
\hline \multirow[t]{2}{*}{ Number of medical problems } & 1 & $141(29.3)$ & $92(65.2)$ & $49(34.8)$ \\
\hline & $\geq 2$ & $135(28.1)$ & $117(86.7)$ & $18(13.3)$ \\
\hline \multirow[t]{2}{*}{ Hypertension } & Yes & $144(29.9)$ & $109(75.7)$ & $35(24.3)$ \\
\hline & No & $337(70.1)$ & $179(53.1)$ & $158(46.9)$ \\
\hline \multirow[t]{2}{*}{ HIV/AIDS } & Yes & $9(1.9)$ & $5(55.6)$ & $4(44.4$ \\
\hline & No & $472(98.1)$ & $283(60.0)$ & $189(40.0)$ \\
\hline Stroke & Yes & $30(6.2)$ & $30(100.0)$ & $0(0.0)$ \\
\hline & No & $451(93.8)$ & $258(57.2)$ & $193(42.8)$ \\
\hline Diabetes Mellites & Yes & 94 (19.5) & $73(77.7)$ & $21(22.3)$ \\
\hline & No & $387(80.5)$ & $215(55.6)$ & $172(44.4)$ \\
\hline Back Pain & Yes & $24(5.0)$ & $16(66.7)$ & $8(33.3$ \\
\hline & No & $457(95.0)$ & $272(59.5)$ & $185(40.5)$ \\
\hline Pneumonia & Yes & $3(0.6)$ & $3(100)$ & $0(0.0)$ \\
\hline & No & $478(99.4)$ & $285(59.6)$ & $193(40.4)$ \\
\hline Osteoporosis & Yes & $31(6.4)$ & $20(64.5)$ & $11(35.5)$ \\
\hline & No & $450(93.6)$ & $268(59.6)$ & $182(40.4)$ \\
\hline
\end{tabular}


Table 1 (continued)

\begin{tabular}{|c|c|c|c|c|}
\hline \multirow[t]{2}{*}{ Variables } & \multirow[t]{2}{*}{ Categories } & \multirow[t]{2}{*}{ Frequency, n (\%) } & \multicolumn{2}{|l|}{ FOF } \\
\hline & & & Yes, n (\%) & No, $n(\%)$ \\
\hline \multirow[t]{2}{*}{ Arthritis } & Yes & $44(9.1)$ & $35(79.5)$ & $9(20.5)$ \\
\hline & No & $437(90.9)$ & $253(57.9)$ & $184(42.1)$ \\
\hline \multirow[t]{2}{*}{ Eye problem } & Yes & $35(7.3)$ & $31(88.6)$ & $4(11.4)$ \\
\hline & No & $446(92.7)$ & $257(57.6)$ & $189(42.4)$ \\
\hline \multirow[t]{2}{*}{ Heart problem } & Yes & $20(4.2)$ & $19(95.0)$ & $1(5.0)$ \\
\hline & No & $461(95.8)$ & $269(58.4)$ & $192(41.6)$ \\
\hline \multirow[t]{2}{*}{ Kidney problem } & Yes & $22(4.6)$ & $19(86.4)$ & $3(13.6$ \\
\hline & No & $459(95.4)$ & $269(58.6)$ & $190(41.4)$ \\
\hline \multirow[t]{2}{*}{ Asthma } & Yes & $22(4.6)$ & $15(68.2)$ & $7(31.8)$ \\
\hline & No & $459(95.4)$ & $273(59.5)$ & $186(40.5)$ \\
\hline \multirow[t]{2}{*}{ Gastritis } & Yes & $10(2.1)$ & $7(70)$ & $3(30)$ \\
\hline & No & $471(97.9)$ & $281(59.7)$ & $190(40.3)$ \\
\hline \multirow[t]{2}{*}{ Environment comfort } & Yes & $345(71.7)$ & $208(60.3)$ & $137(39.7)$ \\
\hline & No & $136(28.3)$ & $80(58.8)$ & $56(41.2)$ \\
\hline \multirow[t]{2}{*}{ Walking aid used } & Yes & $141(29.3)$ & $134(95.0)$ & $7(5.0)$ \\
\hline & No & $340(70.7)$ & $154(45.3)$ & $186(54.7)$ \\
\hline
\end{tabular}

Four hundred one, $83.4 \%$ participants reported that they were not doing regular physical exercise. Most of the participants had social support $(n=330,68.6 \%)$ (Table 1).

\section{Fall-related factors characteristics}

Of the total study participants, $(n=103,21.4 \%)$ of the participants had a history of experienced falling. Fifty one $(10.6 \%)$ of the respondents was hurt by with fall (Table 1).

\section{Disease or treatment related characteristics}

Almost all, $(n=477,99.2 \%)$ of the study participants indicated that there was no functional limitation due to FOF. About $(n=276,57.4 \%)$ of the study participants reported that having confirmed medical conditions. One hundred thirty five, $28.1 \%$ ) of the study participants reported that more than or equal to two medical problems. The commonly reported type of medical problems was hypertension $(n=144,29.9 \%)$, diabetes mellitus $(n=94,19.5 \%)$ and arthritis $(n=44,9.1 \%)$ (Table 1$)$.

\section{Environmental level characteristics}

Among the study participants, $(n=345,71.7 \%)$ were declared that they were living in a comfortable environment and about $(n=141,29.3 \%)$ participants were using walking aids (Table 1 ).
Prevalence of fear of falling among older people 60 years and older in Bahir Dar City

The overall prevalence of FOF among older people 60 years and older who were living in Bahir Dar city was $(n=288,59.9,95 \% \mathrm{CI}, 55.7-64.4 \%)$. Among those who develop FOF $(n=177,70.5 \%)$ were females. The prevalence of FOF $(n=118,90.8 \%)$ was $\geq 71$ year of age. Those who had a history of falling $(n=90,87.4 \%)$ also complained about FOF in the past 12 months.

The prevalence of FOF among study participants with lower levels of education was $(n=27064.4 \%)$. Of the total study respondents, the prevalence of FOF with had confirmed medical problems was $(n=209,75.7 \%)$. The prevalence of FOF among those with had hypertension was $(n=109,75.7 \%), \mathrm{DM}(n=73,77.7 \%)$, and eye problems $(n=31,88.6 \%)$. Those who had anxiety complained about $(n=190,84.8 \%)$ of FOF in the last 2 weeks.

\section{Severity of level of FOF among older people}

Of the total participants, $(n=169,35.1 \%)$ of older people were moderately developed FOF. (Fig. 2).

\section{Factors associated with fear of falling}

Variables that showed a substantial association with FOF in the bivariate analysis were age, sex, educational status, marital status, household income, anxiety, depression, physical exercise, history of falling, injury with fall, confirmed medical conditions, number of 


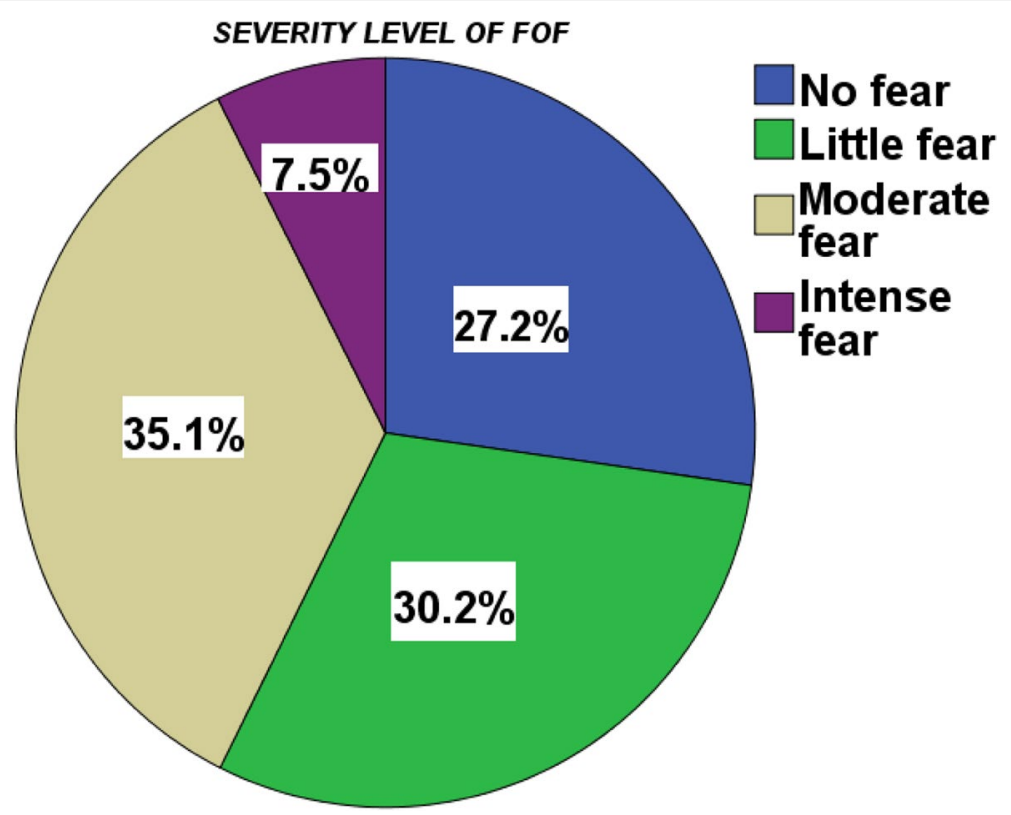

Fig. 2 severity of FOF among older people in Bahir Dar city, Ethiopia

comorbidities, the number types of medications used, and walking aids used.

The variables that showed statistically significant association with FOF during the multivariate analysis were advanced age, female, lower educational level, anxiety, confirmed medical conditions and walking aids used with $p$-value $<0.05$.

The result of this study showed that, being age $\geq 71$ years' of age were approximately four times more likely higher than age in between 60 and 70 years' old (AOR $=4.0 ; 95 \% \mathrm{CI}, 1.65-9.74)$. It was found that female respondents were four times more likely to develop FOF than male respondents $(\mathrm{AOR}=4.2 ; 95 \%$ CI, 2.25-8.01).

Older people who completed the lower level education were almost three times more likely to experience FOF than those who completed higher levels of education $(\mathrm{AOR}=2.7 ; 95 \% \mathrm{CI}, 1.12-6.82$ ).

The result of the current study also showed that elderly people with medical problems were twice as likely to be affected by FOF as those without medical problems $(\mathrm{AOR}=2.0 ; 95 \% \mathrm{CI}, 1.03-3.91)$. Anxiety was nine times higher FOF than don't have anxiety $(\mathrm{AOR}=9.0$; 95\% CI, 4.784-17.07). Older people who used walking aids was nearly 14 times more likely to be affected by FOF than older people who don't have use of it (AOR $=13.8 ; 95 \%$ CI, 5.21-36.63) (Table 2).

\section{Discussion}

This study was conducted to determine the prevalence and associated factors of fear of falling among older people 60 years and older who were living in Bahir Dar City. The overall prevalence of fear of falling among older people aged 60 years and older living in Bahir Dar city was found to be $(n=288,59.9,95 \%$ CI, $55.7-$ 64.4\%). This result indicates that FOF is a common concern for older people living in Bahir Dar. The finding of this study will give a great emphasis, which helps to address realted health problems as aconsquence of FOF in older population at large. Besides, it provides scientific data so as to create a wareness on prevention or health promotion, to reduce the occurrence of fall, to minimize costs and secondary complications. The current study showed FOF severity classification, 7.5\% reported no FOF, 31.1\% reported that little fear, 35.1\% reported moderate fear and $27.3 \%$ reported intense FOF.

The prevalence of the current study was comparable to the similar study conducted in the Longtan community in Beijing, China and Mansoura city, Egypt, which was 58.8 and $64.4 \%$ respectively $[12,35]$. This similarity in these studies could be due to the use of similar cross-sectional study design and the use of the FES-I assessment tool, and the data were collected through interviews with participants. 
Table 2 Factors associated with FOF among older people 60 years and older living in Bahir Dar city, Ethiopia $(n=481)$

\begin{tabular}{|c|c|c|c|c|c|}
\hline \multirow[t]{2}{*}{ Variables } & & \multicolumn{2}{|l|}{ Bivariate } & \multicolumn{2}{|l|}{ Multivariate } \\
\hline & & COR $(95 \% \mathrm{Cl})$ & $P$-value & AOR $(95 \% \mathrm{Cl})$ & $P$-value \\
\hline \multirow[t]{2}{*}{ Sex } & Male & 1.000 & & 1.000 & \\
\hline & Female & $2.5(1.76-3.73)^{*}$ & 0.000 & $4.2(2.25-8.01) * *$ & $<0.001$ \\
\hline \multirow[t]{2}{*}{ Age } & $60-70$ & 1.000 & & 1.000 & \\
\hline & $\geq 71$ & $10.4(5.57-19.65) *$ & 0.000 & $4.0(1.65-9.74) * *$ & 0.002 \\
\hline \multirow[t]{2}{*}{ Education status } & Lower level education & & & & \\
\hline & Higher level education & & & & \\
\hline \multirow[t]{2}{*}{ Marital status } & Currently Married & 1.000 & & 1.000 & \\
\hline & Currently Unmarried & $2.15(1.47-3.14) *$ & 0.000 & $1.2(0.71-2.30)$ & 0.399 \\
\hline \multirow[t]{2}{*}{ Monthly Income } & > ETB 1752 (US\$ 60.98) & 1.000 & & 1.000 & \\
\hline & $\leq$ ETB1752 (US\$ 60.98) & $1.6(1.10-2.35)^{*}$ & 0.013 & $0.5(0.31-1.09)$ & 0.091 \\
\hline \multirow[t]{2}{*}{ Anxiety } & No & 1.000 & & & \\
\hline & Yes & $9.0(5.82-14.12) *$ & 0.000 & $9.0(4.78-17.07)^{* *}$ & $<0.001$ \\
\hline \multirow[t]{2}{*}{ Depression } & No & 1.000 & & 1.000 & \\
\hline & Yes & $5.3(2.91-9.72)^{*}$ & 0.000 & $1.5(0.72-3.35)$ & 0.256 \\
\hline \multirow[t]{2}{*}{ Physical exercise } & Yes & 1.000 & & 1.000 & \\
\hline & No & $4.4(2.67-7.56)^{*}$ & 0.000 & $1.4(0.69-3.18)$ & 0.308 \\
\hline \multirow[t]{2}{*}{ History of fall } & No & 1.000 & & 1.000 & \\
\hline & Yes & $6.2(3.40-11.64) *$ & 0.000 & $2.1(0.63-7.23)$ & 0.223 \\
\hline \multirow[t]{2}{*}{ Injury with fall } & No & 1.000 & & & \\
\hline & Yes & $2.4(0.70-8.56) *$ & 0.158 & $0.2(0.04-1.06)$ & 0.059 \\
\hline \multirow[t]{2}{*}{ Confirmed medical condition } & No & 1.000 & & 1.000 & \\
\hline & Yes & $4.9(3.35-7.37)^{*}$ & 0.000 & $2.0(1.03-3.91) * *$ & 0.038 \\
\hline \multirow[t]{2}{*}{ No of comorbidities } & 1 & 1.000 & & 1.000 & \\
\hline & $\geq 2$ & $3.4(1.89-6.34)$ & 0.000 & $0.5(0.23-1.25)$ & 0.155 \\
\hline \multirow[t]{2}{*}{ No of type of medication used } & $0-3$ & & & & \\
\hline & $\geq 4$ & $7.1(2.52-20.47) *$ & 0.003 & $2.0(0.45-8.89)$ & 0.362 \\
\hline \multirow[t]{2}{*}{ Walking aids } & No & & & & \\
\hline & Yes & $23.1(10.50-50.91)^{*}$ & 0.000 & $13.8(5.21-36.63) * *$ & $<0.001$ \\
\hline
\end{tabular}

NB: COR odds ratio, AOR adjusted odds ratio, ${ }^{*}=$ significant association (on bivariate), ${ }^{* *}=$ significant association (on multivariate, $p$-value $<0.05$ ), $1.000=$ Reference. Model of fitness test (Chi-square $=12.381, \mathrm{df}=8, \mathrm{sig}=0.135$ )

However, the prevalence of this study was lower than that of Diamantina, Brazil (90.4\%), Rio de Janeiro, Brazil (95.2\%), Sao Paulo, Brazil (66.5\%), Iran (90.3\%) and Korea $(70.6 \%)[4,28,29,36,37]$. This variance may be due to discrepancies in methodology, sample size, living environment, and tools used between these studies and our study, which may be one potential explanation for this discrepancy. For instance, a study in Rio de Janeiro, Brazil, was conducted among 742 participants using the local Brazilian version of the falls efficacy scale international outcome assessment method to assess FOF. Similarly, a study in Sao Paulo, Brazil, of 170 older people using the Brazilian version of the falls efficacy scale-international outcome measurement tool for FOF assessment and another study in Korea, of 4164 older people using the longitudinal follow-up study design.

The prevalence of this study was higher than the cross sectional study conducted in the UK (19\%), Spain (41.5\%),
India (33.2\%), Taiwan (53.4\%) and Nigeria (34.4\%) [1, 6, 38-40]. This disparity may be due to the different sample size, the outcome assessment instrument, the methodology, as well as the educational and economic differences.

For instance, a study conducted in Spain among 640 participants using a longitudinal prospective study design and also, instead of using FES-I outcome measurement method, FOF was investigated using a dichotomous yes / no question: "Are you afraid of falling?" Similarly, a study in Taiwan using a community based survey of 3824 participants and FOF was investigated using the same dichotomous yes / no question.

The findings of this study have shown that FOF has a significant association with advanced age, gender, lower educational level, anxiety, confirmed medical conditions and walking aids used.

A substantial association between FOF and gender was found in this study, with females 4.2 times more likely 
to develop FOF than males. This was consistent with a cross-section analysis conducted in the Netherlands, which confirmed that being female was significantly correlated (three times) with the development of FOF [41]. Likewise, other studies done in Hong Kong, China and Korea evidenced that older people have reported a greater FOF in women compared to men $[7,38]$. On the other hand, a systematic review study done by Scheffer et al., 2008 also revealed that, being females had more exposed to FOF than male [5]. In addition, the result of this study supported by studies done in Mexico, Spain, Egypt, Netherland, Thailand and UK, the rate of FOF was higher in female subjects than male $[12,31,32,38$, 39, 42]. This similarity might be due to older women is affected by gender-related factors such as postmenopausal low bone density, faster loss of muscle mass due to reduced hormones [43] and a higher prevalence of chronic non-communicable diseases, and musculoskeletal frailty [44]. On the other side, a studies done in India and Iran, revealed that, no significant relationship was observed between gender and FOF $[4,6]$. This might be because of a small sample of female with FOF observed in both studies done in India and Iran and this might make low statistical power for significance of female in both studies.

The findings of the current study showed an important correlation between FOF and age. Older people who are over 70 years of age experience FOF 4.0 times more than younger elderly people. This finding is confirmed by the previous study in Iran, where older people over 70 years of age are 3.2 more likely to have FOF than those under 70 years of age [4]. Similarly, other studies conducted in Taiwan, Egypt, India, Brazil, Japan, Korea, Mexico, and the Netherlands have found that advanced age is a significant predictor of FOF, which is consistent with the findings of this study $[1,6,12,14,29-31,45]$. The outcome of this study can be justified as advanced age is accompanied by loss of physical, psychological, and physiological change in function is accelerated with aging, which can put older people at risk of falling and FOF.

To the contrary, a study done in the UK, Australia, and the USA, indicated that advanced age not significantly associated with FOF $[13,19,38]$. This may be due to the awareness of older people living in the study area about the use of fall and the FOF prevention program, which in turn leads them both mentally and physically strong.

In this study, FOF was associated with anxiety; older people who had anxiety were found to be 9.0 times more likely to experience FOF than those who did not. This finding is consistent with other studies conducted in China, Netherland, and a systematic review study conducted by Abyad et al. in 2017 revealed a significant relationship between anxiety and FOF $[7,14,46]$. This might lead older people to develop feelings of insecurity either to walk or to do an activity and a reason for a reduction of social participation and this loss of personal contact which in turn increase isolation.

The finding of current study showed that FOF has a significant association with education. Lower education was found to be 2.7 times more likely to acquire FOF than those who have completed higher education level. This result is consistent with another study conducted in the UK, which found that older people with lower levels of education reported higher FOF than higher levels of education [38]. It is also supported by studies conducted in Thailand, Iran, India, and two different studies done in Korea and in which older people with lower educational levels had a significant association with FOF $[4,6,32,45$, 47]. Because of the lower level of education, it may be difficult to establish a coping strategy to minimize FOF, which can lead them to become less active and choose to remain inactive, leading to falling and physical instability.

A significant relation was noted between the presences of confirmed medical health conditions in this current study. Confirmed medical health conditions were found to be 2.0 times more likely to develop FOF than who don't have. This finding is supported by other studies conducted in Thailand, Taiwan, Netherland, India, Egypt, two different studies in Korea and a systematic review study done by Abyad et al., 2017 revealed that a significant association between older people who have medical problems and FOF $[1,6,12,14,32,45-47]$. This poor health status might lead to develop fatigue, weakness, and loss of self-confidence/self-esteem. This may also lead to loss of motivation associated with a reduction of their activity and social interaction and finally this may be a risk factor for activity limitations due to FOF.

Older people who used walking aids during gait were 13.8 times more likely to be affected with FOF than who had not used walking aids in this current study. This result is supported by another study conducted in Egypt, USA, and UK had noted that FOF showed a significant association with use walking aids among older people living in the community $[12,19,38]$. This might be because of older people with FOF had lost confidence in overcoming challenging situation and obstacles in their environment and this may lead them to reduce to maintain balance or control of gait at work or to perform their tasks and because of this older people may enforce to use walking aids for gait.

\section{Limitaion of the study}

Most of the studies were done in developed countries and it was difficult to compare the result of this study to other studies done in a similar setting. 


\section{Conclusion}

The prevalence of fear of falling among older people living in Bahir Dar City is found to be moderate. The findings of the present study showed that fear of falling in the elderly has a major associated with advanced age, female, lower educational level, anxiety, confirmed medical health problems and the use of walking aids. Health office (Ministry of Health), health care providers need to plan and design appropriate for fall and FOF preventive strategies, guidelines or policies as well as allocate appropriate resources for preventive interventions. Health practitioners need to work by providing relevant information to concerned bodies and older people to raise awareness, focus on prevention or health promotion, reduce the risk of falling FOF, minimize costs and associated secondary complications. Further studies with follow up study design recommended.

\begin{abstract}
Abbreviations
ADL: Activity of daily life; AOR: Adjusted Odds Ratio; BMI: Body Mass Index; Cl: Confidence Interval; COR: Crude Odds Ratio; ETB: Ethiopian Birr; FES-I: Falls Efficacy Scale-International; FOF: Fear of falling; GAD-7: General Anxiety Disorder Seven; GDS-SF: Geriatric Depression Scale-Short Form; HOF: History of fall; ORs: Odds Ratios; SD: Standard Deviation; SPSS: Statistical Package for social sciences; UK: United kingdom; U.S.A: United States of America; WHO: World health organization..
\end{abstract}

\section{Supplementary Information}

The online version contains supplementary material available at https://doi. org/10.1186/s12877-021-02534-x.

Additional file 1. English version of questionnaire.

\section{Acknowledgments}

The authors would like to acknowledge the Mekelle University College of health sciences for funding the research. We also like to express special thanks to the Bahir Dar city bureau of labor and social affairs, sub cities, selected kebeles and meshenti town administration for their cooperation. The authors would also like to acknowledge, the study participants, data collectors and supervisors of the study.

\section{Authors' contributions \\ $\mathrm{GB}^{*}$ designed the study, developed the tool and coordinated the data col- lection activity. GB*, BF, GS, HM and MT revised the proposal, carried out the statistical analysis, interpretation of the finding. GS and HM are preparing and writing up of the manuscript. All authors read and approved the final manuscript.}

\section{Authors' information}

Gebremeskel Birhanie - BSc PT, MSc PT, Lecturer of Physiotherapy, School of Medicine, College of Health Sciences, and Tibebe Giyon Specialized Hospital, Bahir Dar University, Bahir Dar, Ethiopia.

Haimanot Melese - BSc PT, MSc PT, Lecturer of Physiotherapy, School of Medicine, College of Health Science and Ayder Comprehensive Specialized Hospital, Mekelle University, Mekelle, Ethiopia.

Gebrerufael Solomon Tsegay - BSc PT, MSc PT, Lecturer of Physiotherapy, School of Medicine, College of Health Science and Ayder Comprehensive Specialized Hospital, Mekelle University, Mekelle, Ethiopia.

Berihu Fisseha Gebremeskel - BSc PT, MSc PT, Assistant professor of Physiotherapy, School of Medicine, College of Health Science and Aksum Referral Hospital, Aksum University, Aksum, Ethiopia.
Molla Teferi - MPH, School of Public Health, College of Health Sciences, Mekelle University, Mekelle, Ethiopia.

\section{Funding}

This study was funded by Mekelle University. The views presented in the article are of the authors and not necessarily express the views of the funding organization. The funders were not involved in the design of the study, data collection, analysis, and interpretation.

\section{Availability of data and materials}

Data will be available upon request from the corresponding author.

\section{Declarations}

\section{Ethics approval and consent to participate}

Ethical clearance was obtained from the ethical review committee of the College of Health Sciences of Mekelle University. Written informed consent was obtained from each of the study participants after being informed in detail about the objective, purpose, benefit, risk, and the confidentiality of the information and the voluntary nature of participation.

\section{Consent for publication}

Not applicable.

\section{Competing interests}

The authors declare that they have no competing interests.

\section{Author details}

${ }^{1}$ Department of Physiotherapy, School of Medicine, College of Health Sciences, and Tibebe Giyon Specialized Hospital, Bahir Dar University, Bahir Dar, Ethiopia. ${ }^{2}$ Department of Physiotherapy, School of Medicine, College of Health Sciences, and Ayder Comprehensive Specialized Hospital, Mekelle University, Mekelle, Ethiopia. ${ }^{3}$ Department of Physiotherapy, School of Medicine, College of Health Sciences, and Aksum Referral Hospital, Aksum University, Aksum, Ethiopia. ${ }^{4}$ Department of Public Health, School of Public Health, College of Health Sciences, and Ayder Comprehensive Specialized Hospital, Mekelle University, Mekelle, Ethiopia.

Received: 23 September 2020 Accepted: 8 October 2021

Published online: 21 October 2021

\section{References}

1. Chang H-T, Chen H-C, Chou P. Factors associated with fear of falling among community-dwelling older adults in the Shih-Pai study in Taiwan. PLoS One. 2016;11(3):e0150612.

2. Uemura K, Shimada H, Makizako H, Doi T, Tsutsumimoto K, Lee S. Effects of mild cognitive impairment on the development of fear of falling in older adults: A prospective cohort study. J Am Med Dir Assoc. 2015; 16:1104 e1109-e1113.

3. Legters K. Fear of falling. Phys Ther. 2002;82(3):264-72.

4. Taghadosi M, Motaharian E, Gilasi $\mathrm{H}$. Fear of falling and related factors in older adults in the city of Kashan in 2017. Arch Trauma Res. 2018;7(2):50

5. Scheffer AC, et al. Fear of falling: measurement strategy, prevalence, risk factors and consequences among older persons. Age Ageing. 2008:37(1):19-24

6. Mane $A B$, et al. Prevalence and correlates of fear of falling among elderly population in urban area of Karnataka, India. J Mid-Life Health. 2014;5(3):150.

7. Liu JY. Fear of falling in robust community-dwelling older people: results of a cross-sectional study. J Clin Nurs. 2015:24(3-4):393-405.

8. Tanjani PT, et al. Study of characteristics of falls among Iranian elders. Saf Promot Injury Prev. 2015;2(4):313-20.

9. Lach HW. Incidence and risk factors for developing fear of falling in older adults. Public Health Nurs. 2005;22(1):45-52.

10. Scheffer AC, Schuurmans MJ, Van Dijk N, Van Der Hooft T, De Rooij SE. Fear of falling: measurement strategy, prevalence, risk factors and consequences among older persons. Age ageing. 2008;37(1):19-24. 
11. Mann $\mathrm{R}$, et al. Exploring the relationship between fear of falling and neuroticism: a cross-sectional study in community-dwelling women over 70. Age Ageing. 2005;35(2):143-7.

12. Saleh $\mathrm{NMH}$, et al. Predictors of fear of falling among community dwelling older adults in Mansoura City, Egypt. Int J Nurs Didactics. 2018;8(08):63-71.

13. Cumming RG, et al. Prospective study of the impact of fear of falling on activities of daily living, SF-36 scores, and nursing home admission. J Gerontol Ser A Biol Med Sci. 2000;55(5):M299-305.

14. Kempen $\mathrm{Gl}$, et al. Socio-demographic, health-related and psychosocial correlates of fear of falling and avoidance of activity in community-living older persons who avoid activity due to fear of falling. BMC Public Health. 2009:9(1):170

15. Wang $M Y$, et al. Activity limitation due to a fear of falling in older adults with eye disease. Invest Ophthalmol Vis Sci. 2012;53(13):7967-72.

16. Means KM, O Sullivan PS, Rodell DE. Psychosocial effects of an exercise program in older persons who fall. J Rehabil Res Dev. 2003;40(1):49-58.

17. Murphy SL, Dubin JA, Gill TM. The development of fear of falling among community-living older women: predisposing factors and subsequent fall events. J Gerontol Ser A Biol Med Sci. 2003;58(10):M943-7.

18. ANRS (Amhara National Regional State). (2009). Retrieved on February 17/ 2019 from http://bahirdarcity.net/population.html.

19. Geographical coordinates of Bahir Dar, Ethiopia. [cited 2019 Jan 22]. Available from: http://dateandtime.info/citycoordinates.php?id=342884.

20. Blanchard RA, Myers AM, Pearce NJ. Reliability, construct validity, and clinical feasibility of the activities-specific fall caution scale for residential living seniors. Arch Phys Med Rehabil. 2007;88(6):732-9.

21. Greenberg SA. Assessment of fear of falling in older adults: the falls efficacy scale-international (FES-I). Disabil Rehabil. 2011;29(2):155-62.

22. Yesavage JA, et al. Development and validation of a geriatric depression screening scale: a preliminary report. J Psychiatr Res. 1982;17(1):37-49.

23. Spitzer RL, et al. A brief measure for assessing generalized anxiety disorder: the GAD-7. Arch Intern Med. 2006;166(10):1092-7.

24. Kroenke K, et al. Anxiety disorders in primary care: prevalence, impairment, comorbidity, and detection. Ann Intern Med. 2007;146(5):317-25.

25. Yardley $L$, et al. Development and initial validation of the Falls Efficacy Scale-International (FES-I). Age Ageing. 2005;34(6):614-9.

26. Dewan N, MacDermid JC. Fall efficacy scale-international (FES-I). J Phys. 2014;60(1):60

27. Cruz DTd, Duque RO, Leite ICG. Prevalence of fear of falling, in a sample of elderly adults in the community. Rev Bras Geriatria e Gerontol. 2017;20(3):309-18.

28. Lopes $\mathrm{K}$, et al. Prevalence of fear of falling among a population of older adults and its correlation with mobility, dynamic balance, risk and history of falls. Braz J Phys Ther. 2009;13(3):223-9.

29. Vitorino LM, et al. Fear of falling in older adults living at home: associated factors Extracted from the project "Avaliação da preocupação dos idosos da comunidade em cair", Escola de Enfermagem Wenceslau Braz, 2012. Rev Escola Enfermagem da USP. 2017;51:e03215. Epub 10 Apr 2017. ISSN 1980-220X. https://doi.org/10.1590/S1980-220X2016223703215. [Accessed 17 Oct 2021]

30. Tomita Y, Arima K, Tsujimoto R, Kawashiri SY, Nishimura T, Mizukami S, Okabe T, Tanaka N, Honda Y, Izutsu K, Yamamoto N, Ohmachi I,
Kanagae M, Abe Y, Aoyagi K. Prevalence of fear of falling and associated factors among Japanese community-dwelling older adults. Medicine. 2018;97(4):e9721. https://doi.org/10.1097/MD.0000000000009721. PMID: 29369207; PMCID: PMC5794391.

31. Agudelo-Botero M, et al. Factors associated with occasional and recurrent falls in Mexican community-dwelling older people. PLoS One. 2018;13(2):e0192926.

32. Thiamwong $L$, Suwanno J. Fear of falling and related factors in a community-based study of people 60 years and older in Thailand. Int J Gerontol. 2017;11(2):80-4.

33. Physical Activity Guidelines for Americans- 2015-2020 Dietary Guidelines. Available at: health.gov.html. Accessed 1 Mar 2019.

34. Organization, WHO, Global recommendations on physical activity for health. Geneva: World Health Organization; 2011.

35. Pu-Lin Y, et al. Prevalence and related factors of falls among the elderly in an urban community of Beijing. Biomed Environ Sci. 2009;22(3):179-87.

36. da Cruz DT, Duque RO, Leite ICG. Prevalência do medo de cair em uma população de idosos da comunidade. Rev Bras Geriatria e Gerontol. 2017;20(3):309-18.

37. Hwang YS, et al. Factors related with fear of falling in the Korean elderly. Korean J Fam Pract. 2017;7(5):640-5.

38. Kumar $\mathrm{A}$, et al. Which factors are associated with fear of falling in community-dwelling older people? Age Ageing. 2014;43(1):76-84.

39. Zhong W, et al. Efficacy of manipulative acupuncture therapy monitored by LSCI technology in patients with severe Bell's palsy: a randomized controlled trial. Evid Based Complement Alternat Med. 2020;2020.

40. Akosile CO Agu CU, Adegoke BOA, Okoye EC, Okeke IA, Emeahara GO. Physical activity, fear of falling, and falls in Nigerian older adults. Common ground Publishers, USA. Int J Aging Soc. 2014;3(2):25-35.

41. Zijlstra G, et al. Prevalence and correlates of fear of falling, and associated avoidance of activity in the general population of community-living older people. Age Ageing. 2007;36(3):304-9.

42. Lee $\mathrm{S}$, Oh E, Hong G-RS. Comparison of factors associated with fear of falling between older adults with and without a fall history. Int J Environ Res Public Health. 2018;15(5):982.

43. Visschedijk JH, et al. Longitudinal follow-up study on fear of falling during and after rehabilitation in skilled nursing facilities. BMC Geriatr. 2015;15(1):161.

44. Ayoubi F, et al. Fear of falling and gait variability in older adults: a systematic review and meta-analysis. J Am Med Dir Assoc. 2015;16(1):14-9.

45. Park J-I, Yang J-C, Chung S. Risk factors associated with the fear of falling in community-living elderly people in Korea: role of psychological factors. Psychiatry Investig. 2017;14(6):894.

46. Abyad A, Hammami SO. Fear of falling in the elderly-an emerging syndrome. Middle East J Age Ageing. 2017;14(3):16-25.

47. Worapanwisit T, Prabpai S, Rosenberg E. Correlates of falls among community-dwelling elderly in Thailand. J Aging Res. 2018;2018(Art. ID 8546085):10. https://doi.org/10.1155/2018/8546085.

\section{Publisher's Note}

Springer Nature remains neutral with regard to jurisdictional claims in published maps and institutional affiliations.

Ready to submit your research? Choose BMC and benefit from

- fast, convenient online submission

- thorough peer review by experienced researchers in your field

- rapid publication on acceptance

- support for research data, including large and complex data types

- gold Open Access which fosters wider collaboration and increased citations

- maximum visibility for your research: over $100 \mathrm{M}$ website views per year

At BMC, research is always in progress.

Learn more biomedcentral.com/submissions 